\title{
¿EL EXVOTO DE DON HERNANDO CORTES?
}

POR

\section{FEDERICO GOMEZ DE OROZCO}

$\mathrm{F}^{\mathrm{N}}$

$\mathrm{N}$ el Instituto de Valencia de don Juan en la ciudad de Madrid, se conserva con gran aprecio, entre otros muchos objetos preciosos alli reunidos, una rara joya a la que se da particular interés, por suponerla vinculada de manera directa con el conquistador de México, don Hernando Cortés.

I a más antigua mención del asunto y la relación del origen de la joya - de Cortés, se encuentran en la Historia de Nuestra Señora de Guadalupe (la de España) escrita por el prior del monasterio jerónimo estable-cido en aquel lugar, fray Gabriel de Talavera, e impresa en Toledo en la imprenta de Tomás de Guzmán el año de 1597 en un tomo en $4{ }^{\circ}$, que ya es obra muy rara.

Descubriendo las preseas del canarín de la Virgen de Guadalıpe, dice el P. Talavera (fol. 178) : "Está también con lo que hemos referido, un escorpión de oto, engaste de otro verdadero que encierra. Ofreciole Fernando Cortés Marqués del Valle, honra, valor y lustre de nuestra España. Dió ocasión a esta dádiva el milagro famoso, que en su defenza obro 
Nuestra Señora; habiendolo mordido un escorpión y derranado tanto veneno por su cuerpo que le puso a peligro de perder la vida. Puesto en este estrecho, volvió los ojos a Nuestra Señora suplicandole le acudiera en tanta necesidad. Fue su magestad servida de oir su petición no permitiendo pasara adelante el daño. El famoso capitan agradecidisimo de la merced, vino de lo más remoto de las Indias a esta santa casa, año de mil quinientos veintiocho y trajo este escorpión de oro y el que le había mordido dentro. Es este engaste y pieza de mucho valor, y de maravilloso artificio en que los indios se aventajaron".

Como el P. Talavera sólo dice que el exvoto es un escorpión de oro, es necesario recurrir a otro cromista del monasterio de Guadalupe, el P. Fray Francisco de San Joseph, para encontrar en su Historia Universal de N. S. de Guadalupe, impresa en Madrid en 1743, en el capitulo IXXI fol. 143, número 11 , la indicación que el exvoto es de oro con algún "mosaico azul, verde y amarilio, con 43 esmeraldas muy claras, grandes y hermosas, las más de ellas labradas con mucha extrañeza, y que tiene también 4 perlas, dos colgantes y otras dos presas en las garras del escorpión, añadiendo que éste es hueco y dentro tiene el cuerpo del que mordió a Cortés".

Esta minuciosa descripción, omitiendo sólo que el escorpión es hueco, la recogió en 1778 un hernano lego del monasterio de Guadalupe, cuyo nombre se ignora, para formar el texto de un curioso libro inventario, en donde copió lo mejor que pudo las principales alhajas de la Virgen de Guadalupe, entre las que figura el exvoto, tal como aquí se reproduce.

No obstante que los dibujos son malos, dan bastante idea de la forma de los objetos que representan, y en cuanto al exvoto contiene algunos detalles en todo de acuerdo con la descripción del mismo, como que el animal aprisiona en las garras sendas perlas y que el colgajo lo forman otras dos, de distinto tamaño, como ptede verse en el dibujo.

En un artículo que publiqué en 1921 en la revista Ethnos 1 con el título de "El exvoto de Hernán Cortés", expuse, porque asi lo encontré en algún documento que lé hace muchos años "que yendo Cortés cierto día a visitar sus campos de moreras ubicados en Yautepec, (actual Estado de Morelos), fué picado por un alacrán, de los muchos muy ponzoñosos que hay en la tierra caliente".

1 El Ethnos, Revista Mensual para vulgarización de estudios antropológicos: sobre México y Centro América.-Tomo I. México, 1920-1922, páginas 219 a 222. con una ilustración. 
DOI: http://dx.doi.org/10.22201/iie.18703062e.1942.8.287

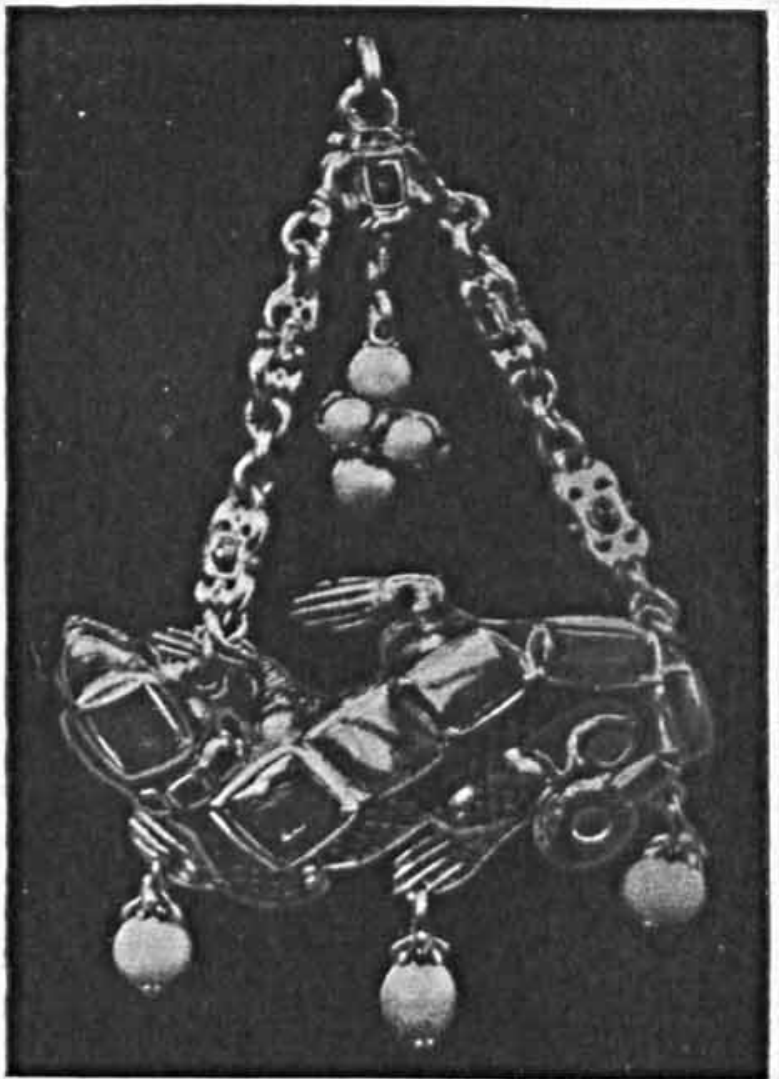

Fig. 1. El exvoto de Cortés, existente en la colección del Instituto de Valencia de Don Juan, Madrid. Visto por el frente. 
DOI: http://dx.doi.org/10.22201/iie.18703062e.1942.8.287

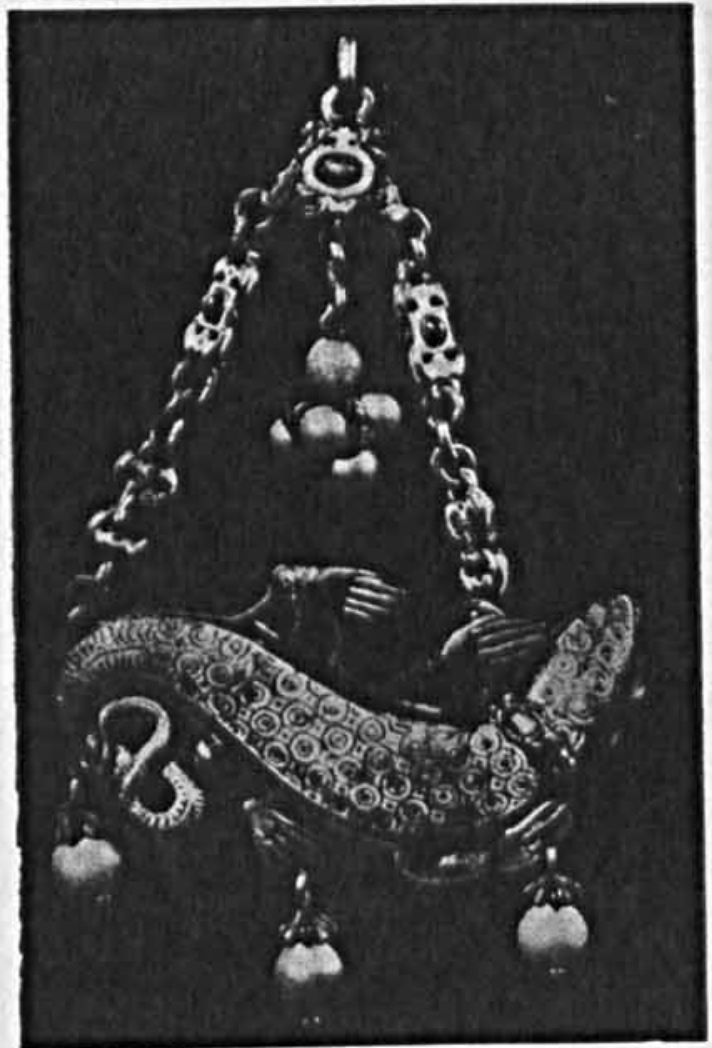

Fig. 2. El exvoto de Cortés. Visto por detrás 
DOI: http://dx.doi.org/10.22201/iie.18703062e.1942.8.287

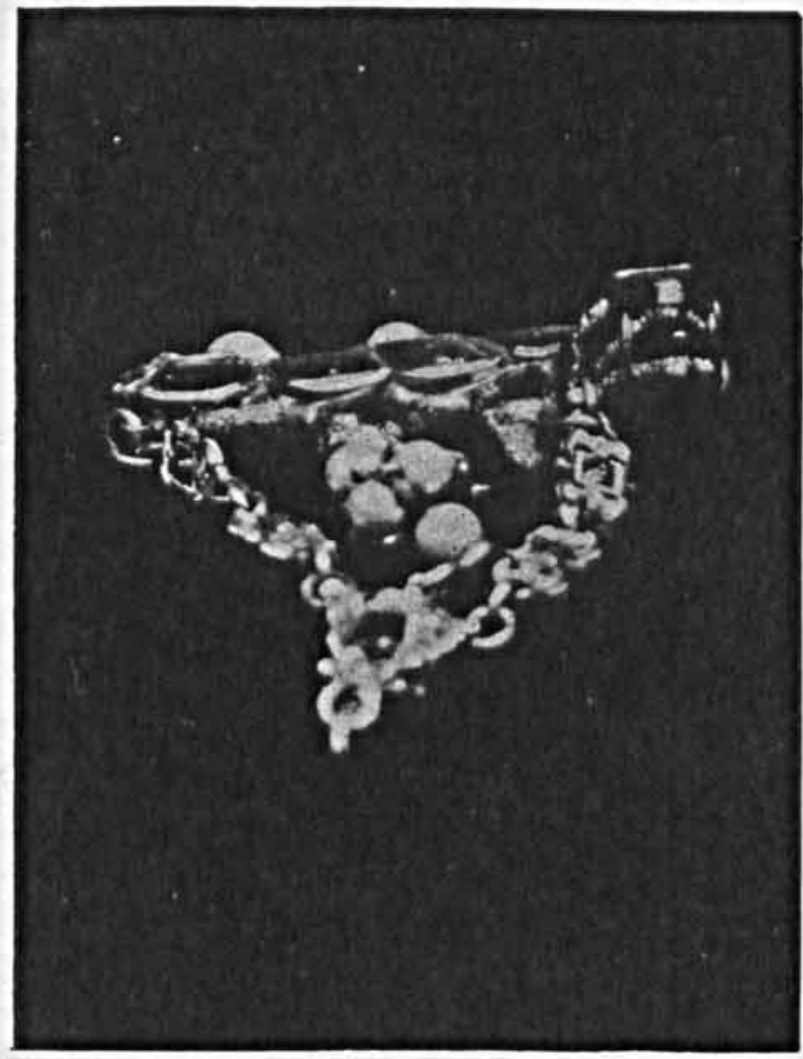

Fig. 3. El exvoto de Cortés. Visto de perfil 


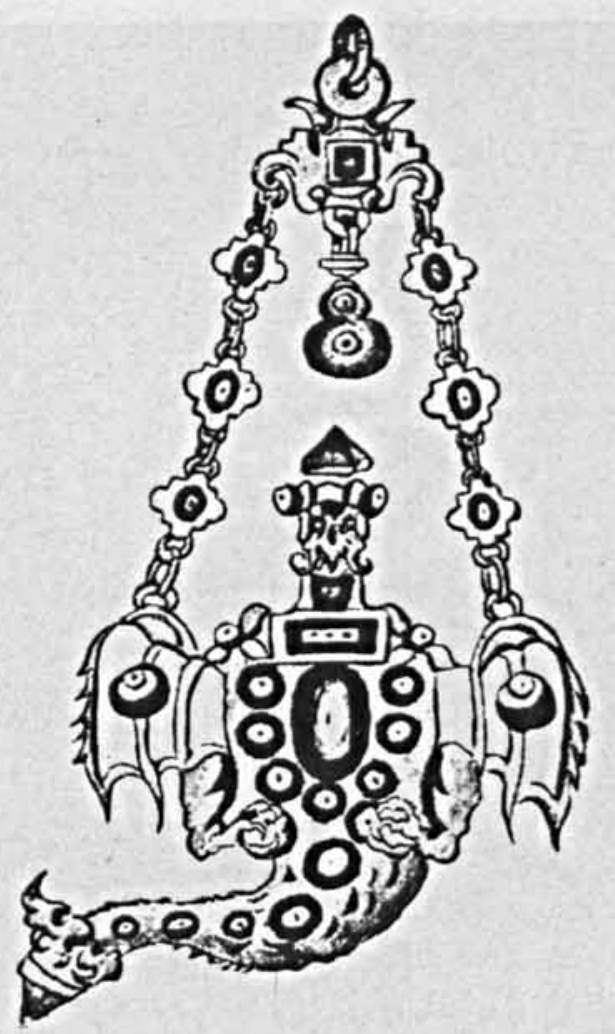

Fig. 4. El exvoto de Cortés, según el dibujo del inventario de alhajas de la Virgen de Guadalupe en Extremadura, España. 
El articulo tuvo suerte y varios escritores han hablado con todo aplomo del alacrán de Cortés, ya refiriéndose al suceso o ya al exvoto; pero en verdad creo que al decir que fué alacrán suiri una equivocación. Lo hice inducido por el dato de tiempo atrás leido, y porque los cronistas ya citados, dicen escorpión, y tomé este nombre por sinónimo de alacrán. No parando mientes en otros datos que consignan los Padres Talavera y San Joseph que en verdad no pueden aplicarse a un alacrán, y si a un reptil de los que también abundan en Yautepec y son todavia denominados escorpiones.

Algunos autores dicen que la alimaña mordió a Cortés, cosa que no puede, ejecutar un alacrán, y al descubrir el escorpión el P. San Joseph y el lego, indican que el animal del exvoto tenia mosaico azul, verde y anarillo, colores impropios para representar a un alacrán y si propios de un reptil, que tiene además cuatro patas armadas de pequeñas uñas a manera de garras, como las que aprisionaban las perlas a que aluden al describir el exvoto.

No hay duda que no fué un arácnido, sino un reptil, el que puso en peligro la vida del conquistälor de México.

Al redactar mi artículo antes altudido, sólo tenía a la vista el mal dibujo del lego anónimo, que toné de la reproducción que de él hizo La llusi tración Española y Americana en su numero XXI correspondiente al dia 8 de junio de 1896, en donde no se puede apreciar bien si el exvoto representa un alacrán o un reptil.

Fué hasta el año de 1932, cuando mi excelente amigo el señor Marqués de San Francisco, tuvo la gentileza de obsequiarme tres fotografias, (las que aquí se reproducen) que a su vez le enviaron de España, con una carta que tanbibién me donó, en donde le dice el patrono del Instituto de Valencia de Don Juan, señor Garcia de Llaniz, que el llamado "Lagarto de Hernán-Cortés", es pieźa interesantísima de la hermosa colección de alhajas antignas que posee este museo (el del Instituto), sin añadir ningún otro dato más que permitiera conocer por qué se prestume ser éste el exvoto de Cortés.

Hasta entonces pude conocer que es un reptil y no un alacrán el que aparece pendiente de ricas cadenillas de oro, para ser prendido sin dida al vestido de la Virgen de Guadalupe, según es costumbre hacerlo con los exvotos.

Pero mirando con mayor atención las fotografías de la joya del Instituto, me entró la duda si realmente es éste el exvoto que personal- 
mente llevara el Conquistador, y creo que no es: Aunque esta guarnecida con esmeraldas, tanto en el dorso del reptil como en el cuello, sólo tiene 14 gemas y no se ve ni por asomo dónde pudieran estar las restantes hasta completar el número de 43 que dicen tenía el exvoto; en cuanto a las perlas, hay también discrepancia: no son cuatro, sino nueve, seis en el colgajo al centro de lás cactenas y tres en el cuerpo del reptil, una de etlas pendiente de la cola, de la que no se habla para nada en la descripción, ni aparece en el dibujo del hermano lego, siendo, además, distinta la forma de la cola en la alhaja del Instituto y la del dibujo. En cuanto a las de las extremidades, mano y pata izquierdas, no las aprisiona en las garras, como claramente se ven en el dibujo, sino penden de una perforación que hay entre los dedos del rejtil.

Es, pues, evidente que entre el dibujo, aun contando con sts imperfecciones técnicas, y la joya existente en Madrid, hay notables diferencias. Se encuentra cierta sinilitud en la forma de las cadenas, pero en cuanto al animal no veo parecido alguno y sí grandes discrepancias, pues mientras en el dibujo sí se reconoce cierta técnica aborigen mexicana, en la joya se advierte marcada influencia europea, italiana diria yo, y notable parecido, en cuanto al estilo, a otro exvoto que reprodujo el lego y representa el inconfundible león de San Marcos, símbolo de la República de Venecia.

¿A qué atribuir estas diferencias y por qué se tiene por el exvoto de Cortés, el existente en Madrid? Ignoro cớmo, cuándo y en qué forma llegó al Instituto la alhaja que allí suponen es la misma del conquistador; es indudable que hay alguna razón para identificarla como tal; pero también creo, que pudo habérsele dado esa atribución por la semejanza en cuanto a que una y otra representaban un reptil, o bien, que el exvoto fuera rehecho y modificado en época posterior al dibujo del lego, quien lo encontró tan igual a la descripción del $P$. San Joseph, que no tuvo empacho alguno de tomar sus propias palabras, para insertarlas en el texto del correspondiente dibujo. Ojalá y algún perito en la materia, teniendo en cuenta todo lo aquí expuesto, con el llamado "Lagarto de Cortés" a la vista, nos dé su opinión en el asunto y una minuciosa descripción de la joya, pues de ser la propia del Conquistador, vendrá a realzar más su importancia histórica, el raro mérito de su origen. como una de las primeras manifestaciones de la pericia técnica de los orfebres indígenas mexicanos. 